\title{
Coefficient Of Discharge For A Combined Hydraulic Measuring Device
}

\author{
H. A. M. Hayawi Dr. G. A. M. Hayawi Amal A. G. Alniami \\ Water Res. Eng. Dept/College of Engineering \\ University of Mosul
}

\begin{abstract}
The aim of this study is to investigate the coefficient of discharge for a combined hydraulic measuring device. For this purpose nine combined models were constructed and manufactured of an aluminum plates of $2 \mathrm{~mm}$ thick, the shapes of the models are of rectangular weir with different width $(B=8,10,12 \mathrm{~cm})$ is used over a semi-circular gate of a constant diameter $(d=12 \mathrm{~cm})$ the distance below the weir edge and the semi-circular gate $\mathrm{y}$ is changed three times $((y=5,10,15 \mathrm{~cm})$. The analysis of results show that $C d$ increase as $(h / d)$ increase and for a constant value of $(h / d) C d$ increase as the width $B$ increase, the values of $C d$ range from around 0.522 to 0.853 with an average of 0.695 . Also $C d a$ decrease as the parameter $(y / d),(B / d)$ and $(b / W)$ increase and at a constant values of that parameters $C d a$ increase as $y$ increase, and the values of $C d a$ range from around 0.61 to 0.74. A multi regression model to estimate $C d$ for the combined device is estimated with percentage of error $\pm 10 \%$.
\end{abstract}

Keywords: combined orifice, combined weirs.

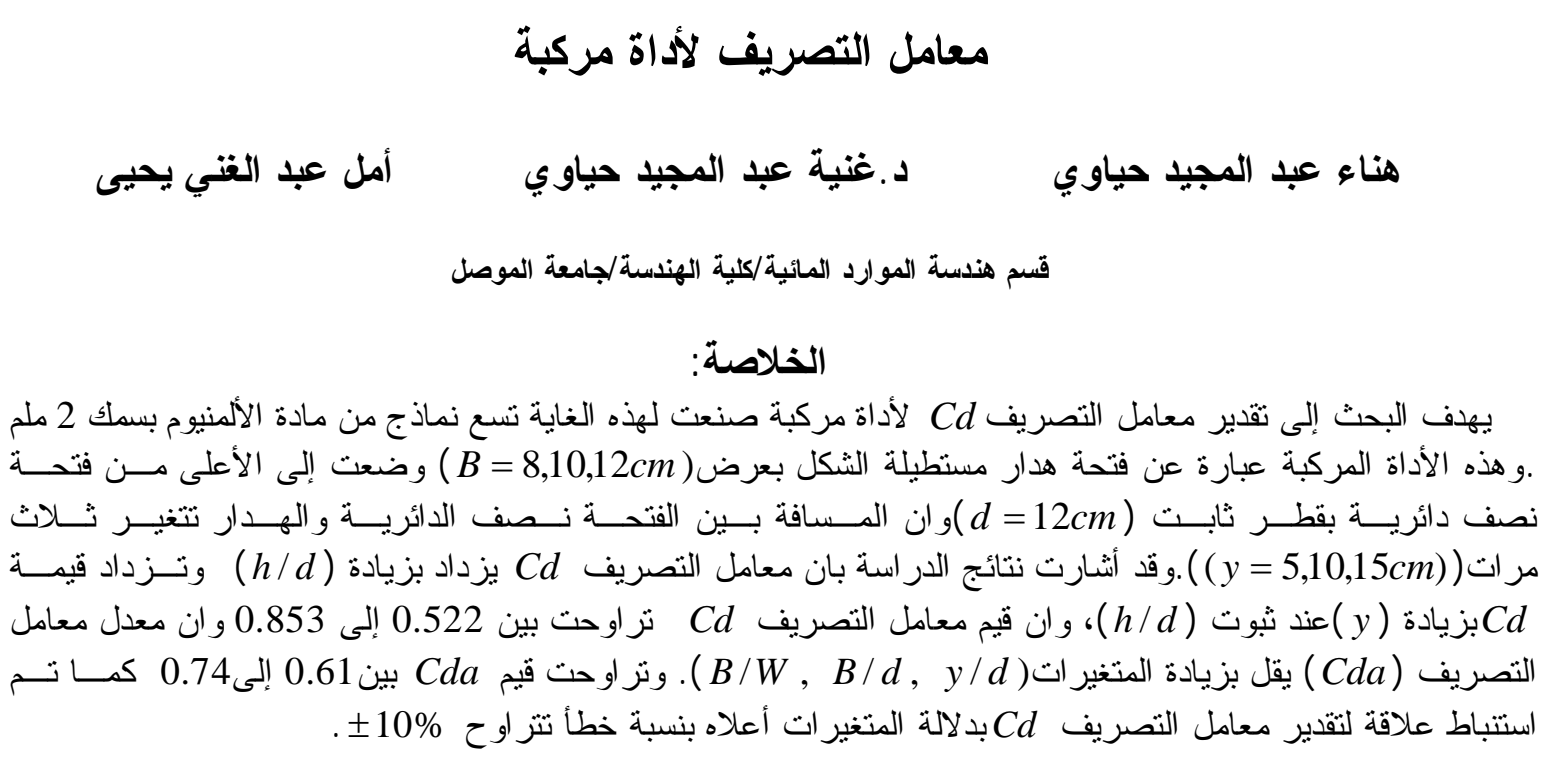

Received 10 Sep. 2008

Accepted 27 Jan. 2009 


\section{Al-Rafidain Engineering $\quad$ Vol.17 $\quad$ No.6 $\quad$ Dec. 2009}

\section{Introduction:}

Weir structures are used in canal, river and reservoir application for flow measurement. Both weirs and gates are used frequently for discharge measurements in open channels. Works concerning the use of sluice gates as discharge measurement structure may be found, e.g by Rajaratham(1977). Weirs and gates may be combined together in one device yielding a simultaneous flow over the weir and below the gate (Negam,2002). The flow through combined devices may be free when both the flow over weir and below the gate are free or it is termed submerged when the flow below the gate is submerged. The simultaneous discharge can be obtained by adding the overflow discharge to the under flow discharge and making use of interaction factor (Negam,1996 and Negam et al.,2000) . Comprehensive review of the studies dealing the simultaneous flow over weirs and below gates can be found in(Negam et al.,2002) Negam,2002 propose a general model for predicting the combined flow over weirs and below gates for both free and submerged gates conditions utilizing the basic discharge equations of the weir and gates and an artificial neural networks to predict the simultaneous discharge over weirs and below gates when they have unequal contractions. Then the results of both methods are compared. The aim of the present study is to investigate experimentally the free flow through a combined rectangular weir and below a semi-circular gate.(a combined device) and to propose a model for predicting the discharge coefficient through it.

\section{Theoretical analysis:}

Figure 1 shows definition sketch for the free flow over rectangular weir and through submerged semi- circular gate (combined device) of different contraction.

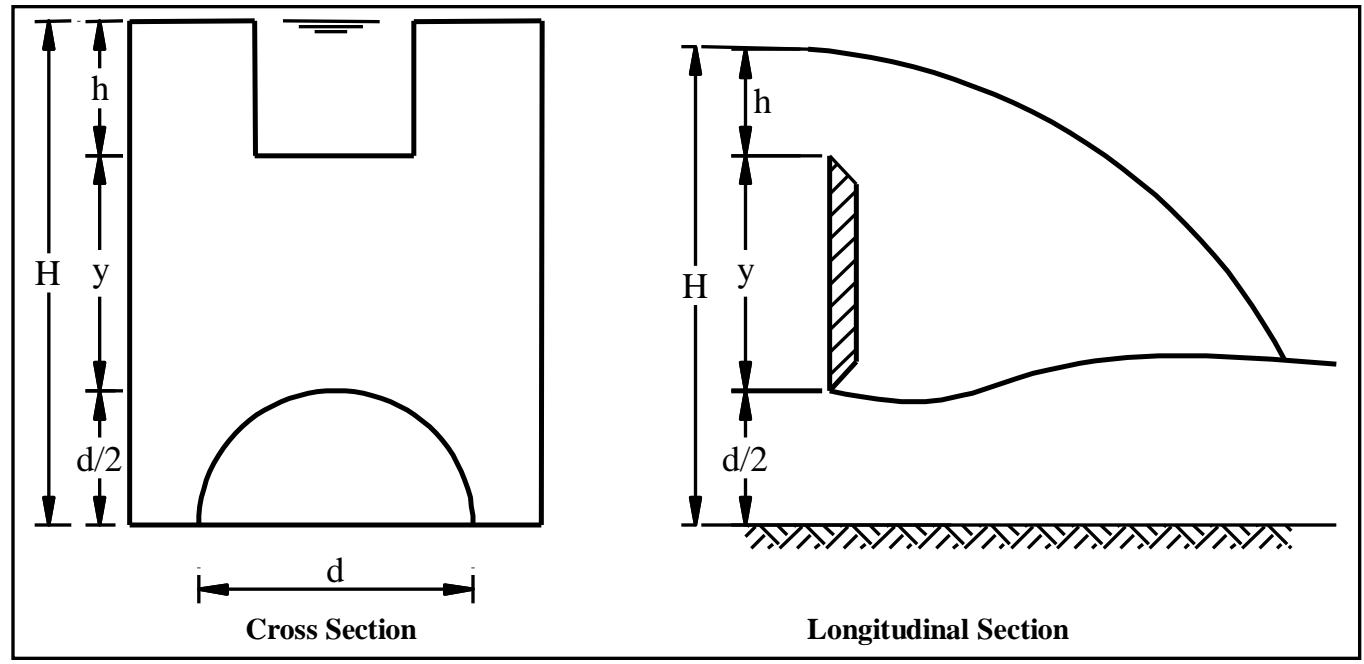

Fig.1. Definition Sketch For the Combined Hydraulic Measuring Device

$Q_{\text {the }}$ is the total discharge through the combined device which is calculated as follows.

$Q_{\text {the }}=Q_{w}+Q_{g}$

$Q_{g}$ : discharge through a semi- circular gate $\left(\mathrm{m}^{3} / \mathrm{s}\right)$.

$Q_{w}$ : discharge through a rectangular weir $\left(\mathrm{m}^{3} / \mathrm{s}\right)$.

$Q_{\text {the }}$ : total theoretical discharge through combined device $\left(\mathrm{m}^{3} / \mathrm{s}\right)$ 
$Q_{w}=\frac{2}{3} \sqrt{2 g} B h^{\frac{3}{2}}$

$Q_{g}=\frac{\pi \sqrt{2 g}}{8} d^{2} H^{\frac{1}{2}}$

$g$ :acceleration due to gravity $\left(\mathrm{m} / \mathrm{s}^{2}\right)$.

$d:$ the diameter of the gate $(m)$.

$h:$ the head through the rectangular weir $(m)$.

$y$ : the distance below the weir and over the gate edge $(m)$.

$H:$ the total head $H=h+y+\frac{d}{2}(m)$.

$B:$ the width of the rectangular weir $(m)$.

$Q_{a c t}=\mathrm{Cd} \mathrm{Q}_{\text {the }}$

$Q_{a c t}:$ the total actual discharge through the standard rectangular weir $(l / s)$

$C d$ : the coefficient of discharge for the combined device

For flow through a rectangular weir and below a semi- circular gate (combined device), the discharge $\mathrm{Q}_{\text {act }}$ can be expressed by the following functional relation ship:

$$
Q_{a c t}=f(W, d, y, h, B, H, g, \rho, \mu, \sigma)
$$

$\rho$ :density of water $\left(M L^{-3}\right), \mu$ : dynamic viscosity $\left(M L^{-1} T^{-1}\right), \sigma:$ surface tension $\left(M T^{-2}\right)$. Based on eq. 5 and using dimensional analysis (Buckingham $\pi$ Theorem) shows the following:

$\frac{Q_{a c t}}{\left(g^{\frac{1}{2}} d^{\frac{5}{2}}\right)}=f\left(\frac{y}{d}, \frac{B}{d}, \frac{h}{d}, \frac{H}{d}, \frac{B}{W}, \frac{\mu}{\rho g^{\frac{1}{2}} d^{\frac{3}{2}}}, \frac{\sigma}{\rho g d^{2}}\right)$

But $\frac{\mu}{\rho g^{\frac{1}{2}} d^{\frac{3}{2}}}=\frac{1}{\operatorname{Re}}$, where Re is Reynolds number

and $\frac{\sigma}{\rho g d^{2}}=\frac{1}{W e}$ and We is Weber number

In terms of $C_{d}$ eq. (6) can be written as

$C d=f\left(\frac{y}{d}, \frac{B}{d}, \frac{h}{d}, \frac{H}{d}, \frac{B}{W}, \operatorname{Re}, W e\right)$

The effect of Reynolds number and Weber number is assumed to be negligible for the combined device except at a very low head

\section{Experimental set- up:}

The experiments were carried out in horizontal rectangular channel of $10 \mathrm{~m}$ length, with cross-section $0.3 \mathrm{~m}$ wide and $0.45 \mathrm{~m}$ high. The walls of the channel were a toughened 


\section{Al-Rafidain Engineering $\quad$ Vol.17 $\quad$ No.6 $\quad$ Dec. 2009}

glass with number of perpex panels incorporated. The bed of the channel consisted of stainless -steel plates. A pair of a justable instrument rails were fitted on the top of the channel sides through the working length of the channel two movable carriages equipped with point gauges were mounted on the rails. Fig. (2) shows the details of the channel used in this study. All series of experiment were conducted in the hydraulic laboratory of water resources engineering department, college of engineering, university of Mosul.

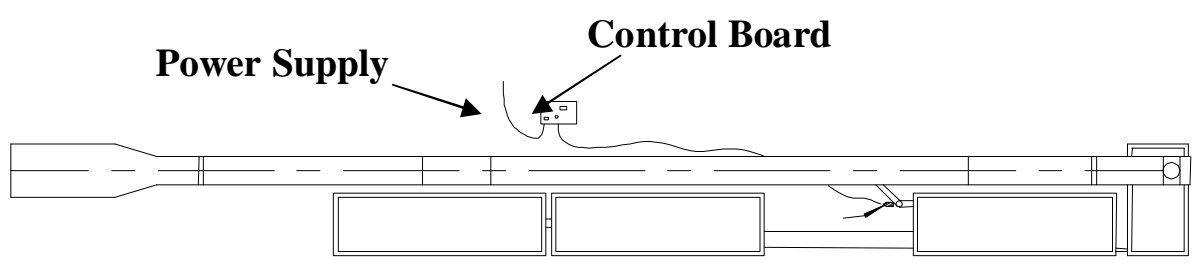

\section{Plane of Channel}

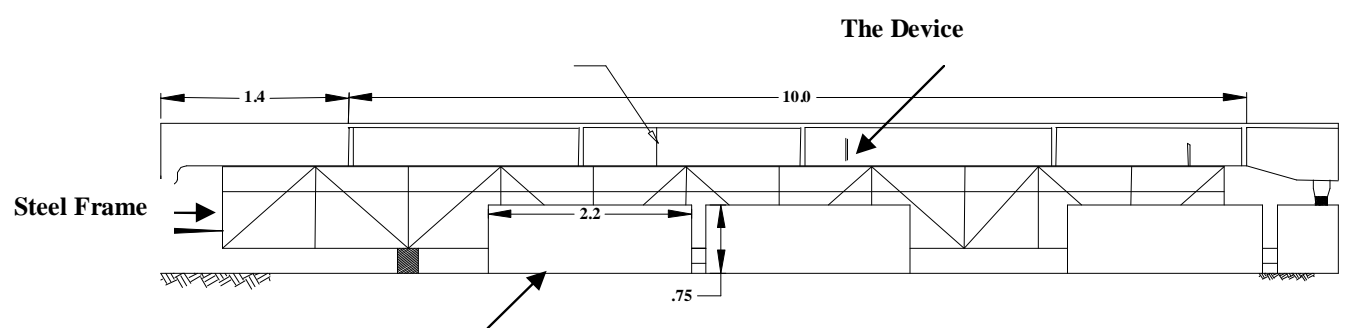

Storage Tank

Side View of The Channel

Fig.2. Channel Lay Out

Nine combined device model were constructed and manufactured of an aluminum plates $2 \mathrm{~mm}$ thick, these models were of a rectangular weir with different width ( $B=8,10,12 \mathrm{~cm}$ ) over a semi-circular gate of constant diameter $d=12 \mathrm{~cm}$, the distance below the weir edge $y$ and the semi-circular gate is changed three times $(y=5,10,15 \mathrm{~cm})$. The detail of the combined device used is shown in table (1).

Table (1): Details of Combined Device Tested

\begin{tabular}{|c|c|c|c|}
\hline Model No. & Run No. & Width of Weir(B cm) & Distance $(\mathrm{Y} \mathrm{cm})$ \\
\hline 1 & $1-6$ & 8 & 5 \\
2 & $7-12$ & 8 & 10 \\
3 & $13-17$ & 8 & 15 \\
4 & $18-23$ & 10 & 5 \\
5 & $24-29$ & 10 & 10 \\
6 & $30-34$ & 10 & 15 \\
7 & $35-40$ & 12 & 5 \\
8 & $41-46$ & 12 & 10 \\
9 & $47-51$ & 12 & 15 \\
\hline
\end{tabular}




\section{Hayawi : Coefficient Of Discharge For A Combined Hydraulic Measuring Device...}

All combined devices were fixed at distance $1.5 \mathrm{~m}$ up stream from the channel outlet section and for actual discharge measurement a full width thin-plate sharp-crested rectangular weir of $15 \mathrm{~cm}$ height were used. The weir was manufactured according to British standards (1965). The head up-stream of the weir and the combined device was measured with a precision point gauges whose least count $0.1 \mathrm{~mm}$ and the temperature was around $20^{\circ} \mathrm{C}$ during all the experiments.

\section{Analysis of Results:}

a- Variation of $C d$ with $\frac{h}{d}$

The effect of $\frac{h}{d}$ on $C d$ can be studied by conducting tests on a combined device. The discharge coefficient $C d$ was obtained using equation 4 in which $Q_{a c t}$ is the discharge measured by the standard rectangular weir. Figures 3, 4, and 5 shows the relation ship between $\frac{h}{d}$ and the coefficient of discharge $C d$ for a width of the rectangular weir opening $(B=8,10,12 \mathrm{~cm})$ respectively, it can be concluded that $C d$ increase as $\frac{h}{d}$ increase. And for a given constant width $B$ the value of $C d$ increase as the distance( $y$ ) above the gate opening and below the rectangular weir increase.

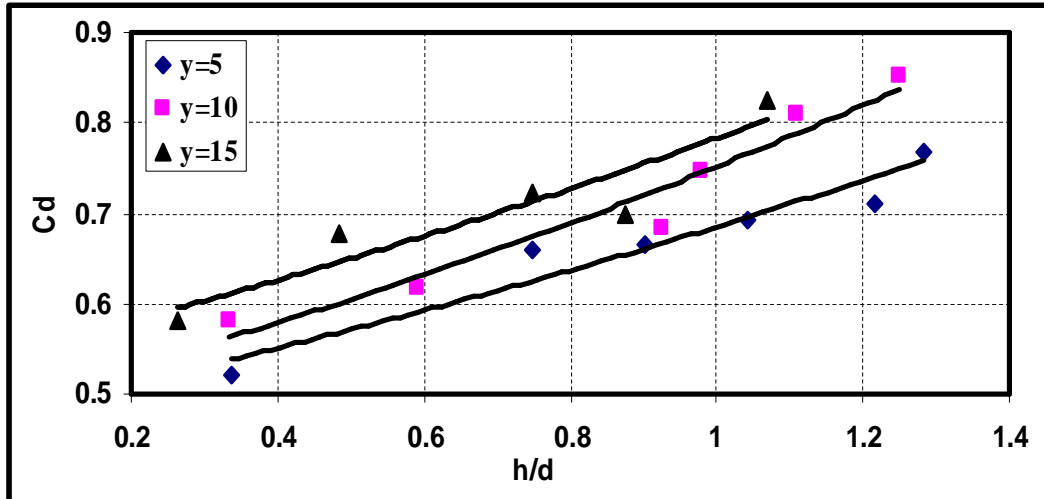

Fig.3 Varation of $\mathrm{Cd}$ with $\mathrm{h} / \mathrm{d}$ for $\mathrm{B}=8 \mathrm{~cm}$

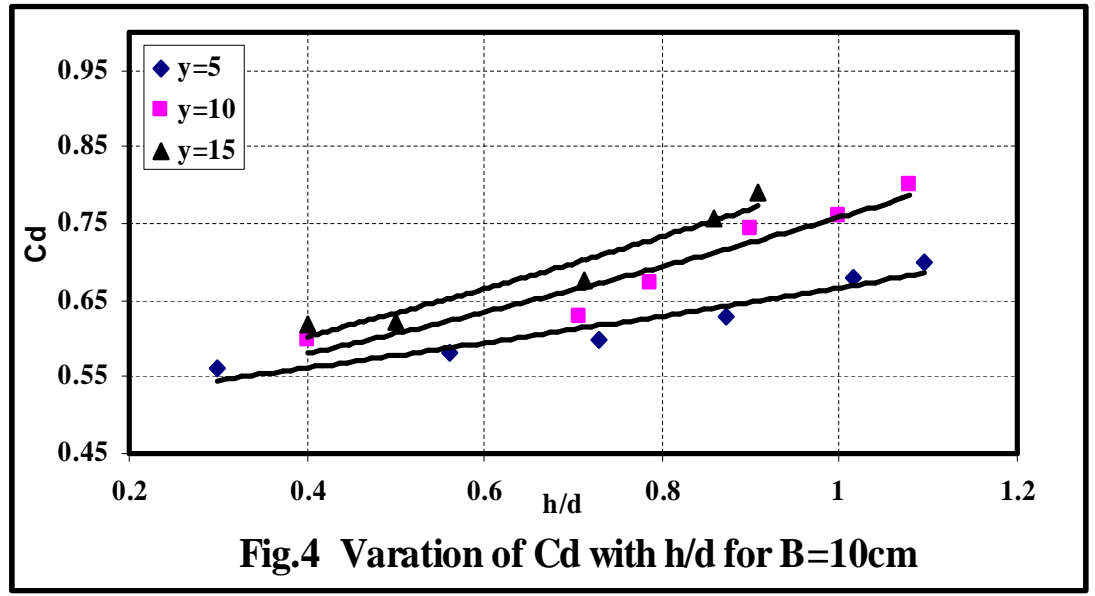


Al-Rafidain Engineering $\quad$ Vol.17 $\quad$ No.6 $\quad$ Dec. 2009

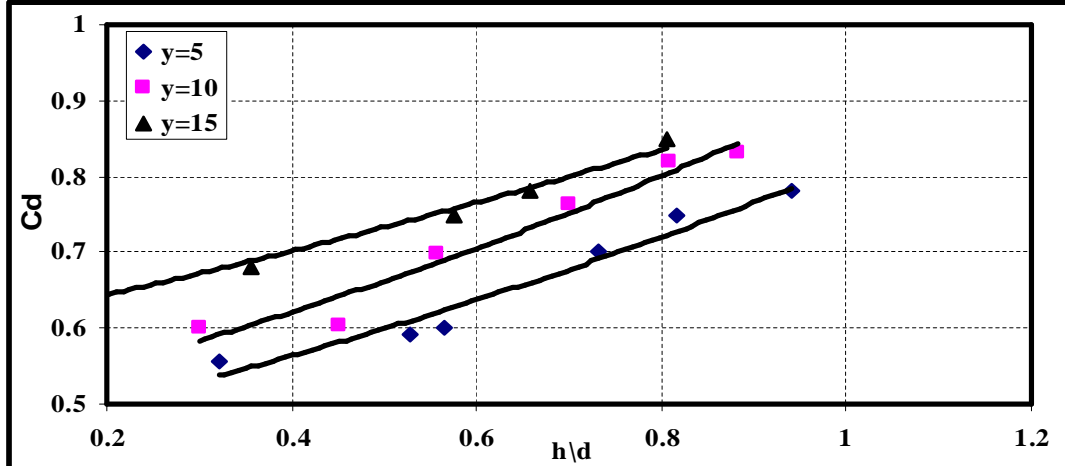

Fig.5 Varation of $\mathrm{Cd}$ with $\mathrm{h} / \mathrm{d}$ for $\mathrm{B}=12 \mathrm{~cm}$

b- Variation of $C d a$ with $\frac{y}{d}, \frac{B}{d}$, and $\frac{B}{W}$

Figures $(6,7$, and 8$)$ shows the relation ship between the average discharge coefficient $C d a\left[\left(C d a=\frac{\sum C d}{n}\right), \mathrm{n}=\right.$ number of runs for each models $]$ and the value of the parameters $\frac{y}{d}, \frac{B}{d}$ and $\frac{B}{W}$ respectively. From the Figures it was seen that the average coefficient discharge $C d a$ decrease as the values of the parameters, $\frac{y}{d}, \frac{B}{d}$ and $\frac{B}{W}$ increase and at a constant values of these parameters $C d a$ increase as $(y)$ increase.
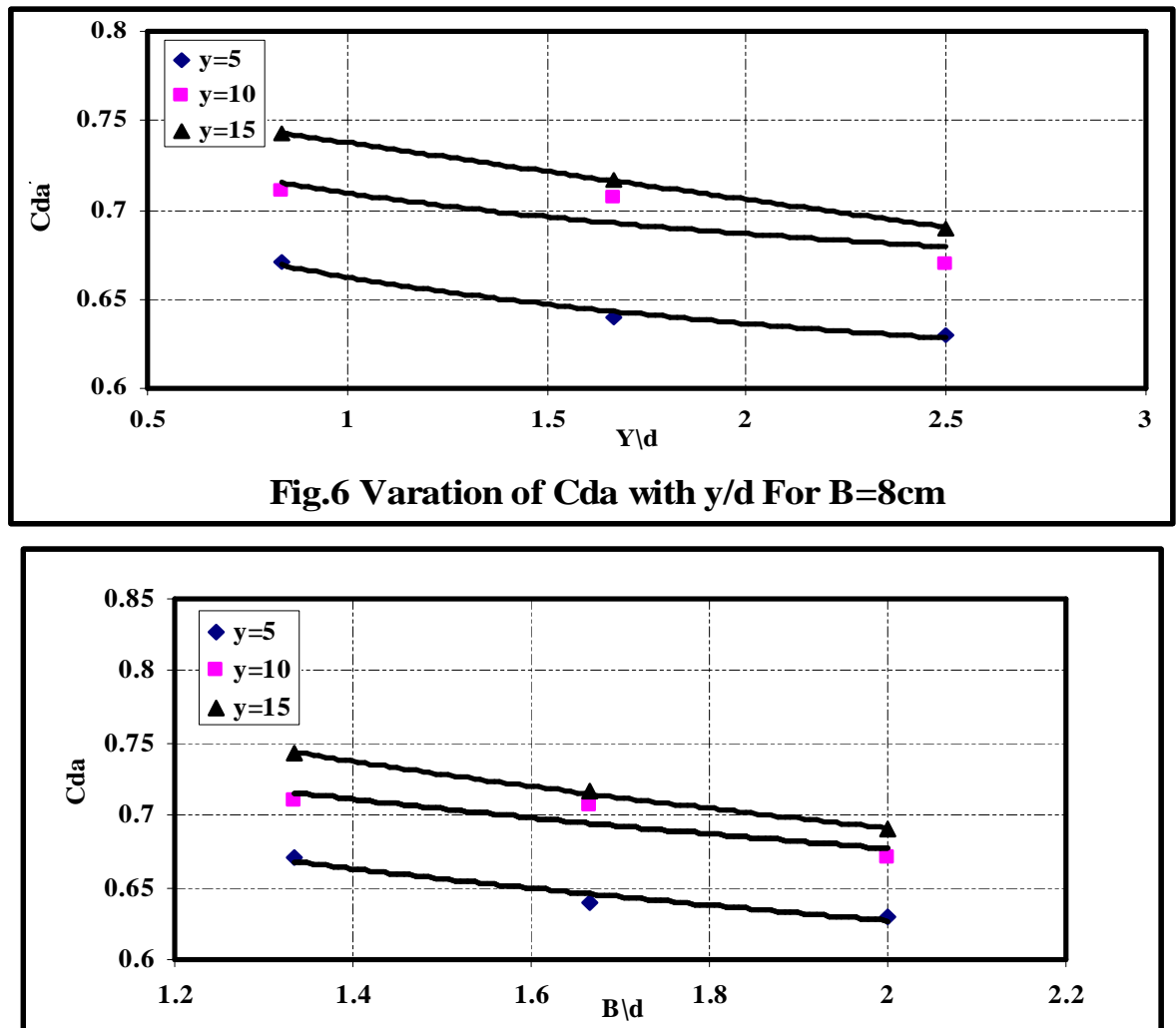

Fig.7 Varation of Cda with $B / d$ For $B=12 \mathrm{~cm}$ 


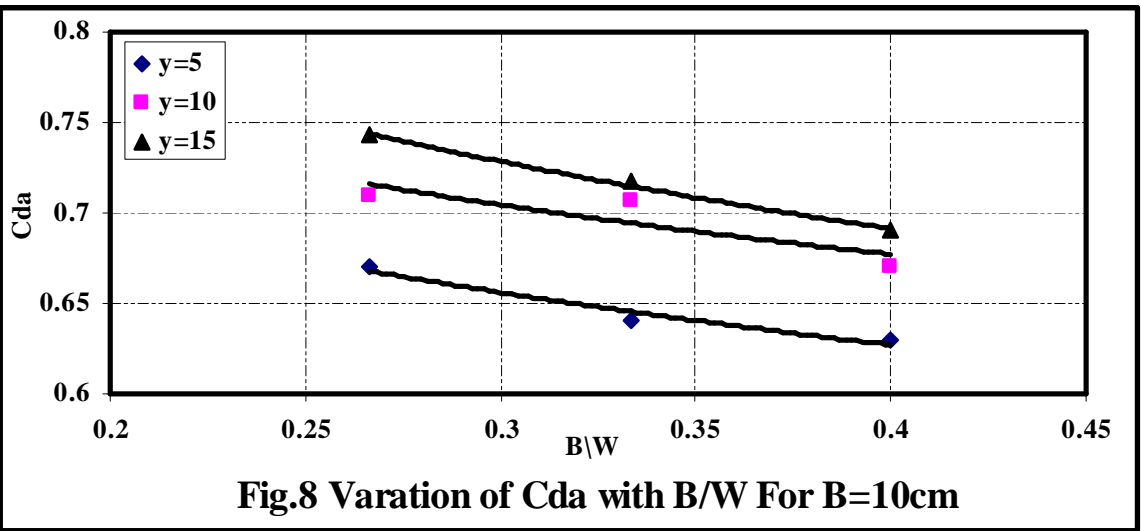

c- Based on dimensional -analysis multiple regression analysis was applied to the data and $\frac{h}{d}, \frac{y}{d}, \frac{B}{d}$, and $\frac{B}{W}$ are found to represent the observed coefficient of discharge $C d$ better than any other combination of the dimensionless numbers in equation (7). The best fit is:-

$C d=0.38\left(\frac{H}{d}\right)^{0.811}\left(\frac{y}{d}\right)^{-0.163}\left(\frac{B}{d}\right)^{-0.107}\left(\frac{B}{W}\right)^{0.376}$

$R^{2}=0.802$.

Where $R^{2}$ is the coefficient of determination d-Variation of experimentally observed values of $C d$ and values predicted by equation (8) is shown in fig.(9), which shows a good agreement.

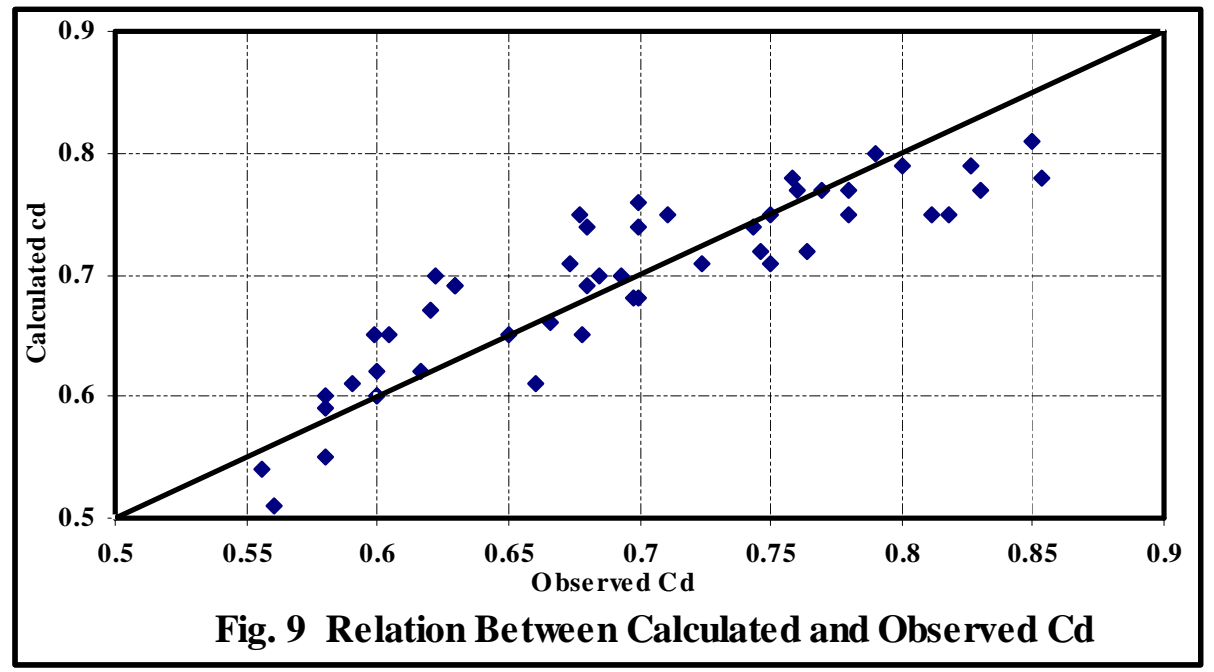

The percentage of error between the observed and calculated values of $C d$ is calculated as follows:

$$
\% \text { Error }=\frac{(C d) o b s-(C d) c a l}{(C d) o b s} \%
$$

The error distribution in predicting coefficient of discharge (observed $C d$ ) from eq.(4) is shown in fig.(10) the percentage of error is within $\pm 10 \%$ for the total experimental 
data .Therefore the combined hydraulic measuring device presented in this study is said to be accurate discharge measuring device .

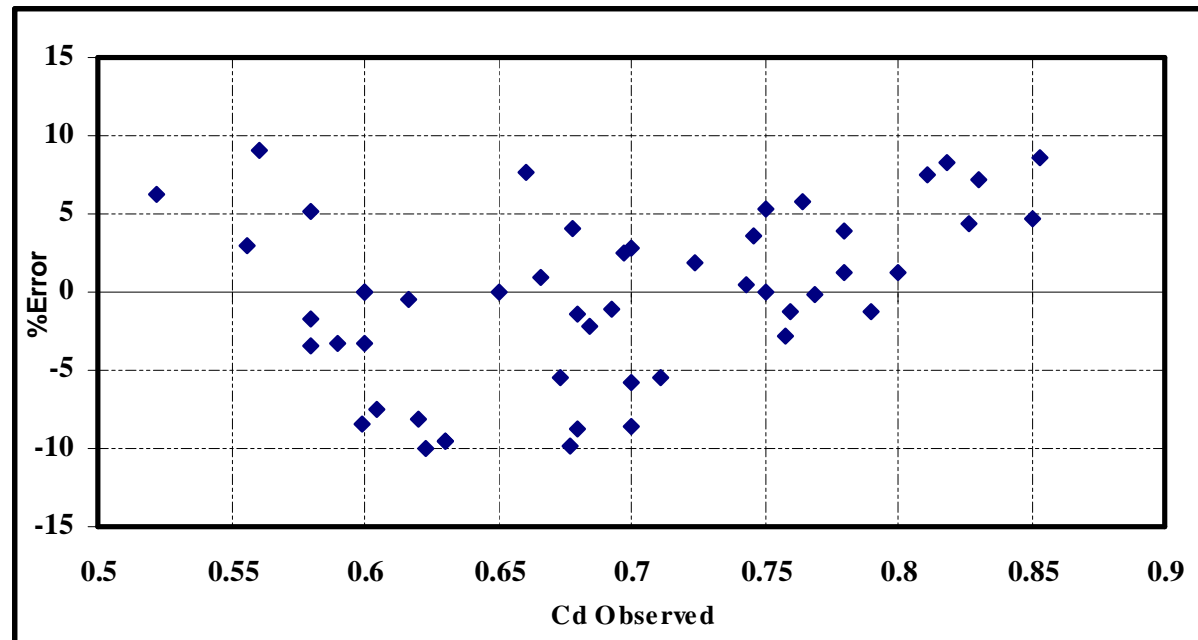

Fig.10 Error Dis tributionin in Observed Cd

\section{Conclusions:}

Based on the analysis of experimental study on flow through a combined hydraulic measuring device, the following conclusions are withdrawn:

1. The coefficient of discharge $C d$ increase as the parameter $\left(\frac{h}{d}\right)$ increase, and the values of Cd range from 0.522 to 0.853 with an average value 0.695 .

2. The average coefficient of discharge $C d a$ decrease as the parameters ( $\frac{y}{d}, \frac{B}{d}$, and $\frac{B}{W}$ ) increase, with range from0.61 to 0.74 .

3. A multi regression analysis were applied to estimate the coefficient of discharge $C d$ in relation with the parameters $\left(\frac{H}{d}, \frac{y}{d}, \frac{B}{d}\right.$, and $\left.\frac{B}{W}\right)$ with percentage of error $\pm 10 \%$ for all data.

\section{Notations:}

$Q_{w}$ : discharge through a rectangular weir $\left(\mathrm{m}^{3} / \mathrm{s}\right)$.

$Q_{g}$ : discharge through a semi- circular gate $\left(\mathrm{m}^{3} / \mathrm{s}\right)$.

$g:$ acceleration due to gravity $\left(\mathrm{m} / \mathrm{s}^{2}\right)$.

$d:$ the diameter of the gate $(m)$.

$B:$ the width of the rectangular weir $(m)$.

$h$ : the head through the rectangular weir $(m)$.

$y$ : the distance below the weir and over the gate edge $(m)$.

$H$ : the total head ; $H=h+y+\frac{d}{2}(m)$.

$Q_{a c t}$ : the total actual discharge through the standard rectangular weir $\left(\mathrm{m}^{3} / \mathrm{s}\right)$.

$Q_{\text {the }}$ : total theoretical discharge through combined device $\left(\mathrm{m}^{3} / \mathrm{s}\right)$.

$C d a$ : average of coefficient of the discharge of the combined device

$C d$ : the coefficient of the discharge of the combined device 


\section{Hayawi : Coefficient Of Discharge For A Combined Hydraulic Measuring Device...}

Re:is Reynolds number

$W e:$ is Weber number

$W$ :channel width $(m)$.

$\rho:$ density of water $\left(\mathrm{kg} / \mathrm{m}^{3}\right)$

$\mu$ : dynamic viscosity $($ Pa.s $)$

$\sigma:$ surface tension $(N / m)$

\section{References:}

1. British Standard Institution , 1965".Methods of Measurements of Liquid Flow in Open Channels". London, England.

2. French, R.H(1986)."Open-Channel Flow Hydraulics,pp.343-353.Cgraw Hill Book Co., Newyurk.

3. Negm, A.M.1996."Discharge Prediction Model for Simultaneous Underflow Overflow". Proc. $6^{\text {th }}$.Int.Symp. on Flow Modeling and Turbulence Measurements. Florida, USA, sep.8-10.

4. Negm, A.M,Abedel-Al.G.M.and Ei-saiad A.A.2000. "Generalized Discharge Equation for Proposed Simultaneous Flow Structures". Proc.Al-A zhar Eng $6^{\text {th }}$ Inst.conf.(AEIC). Cairo Egypt. sep. 1-4.4:247-257.

5. Negm, A.M.2002a" Prediction of Hydraulic Design Parameters of Expanding Stilling Basins Using Neural Networks". Egyption Journal of Engineering Science and Technology(EJEST).6(1):1-24.

6. Negm, A.M.2002b."Analysis and Modeling of Simultaneous Flow Through Box Culverts and Over Contracted Broad-Crested Weirs" . proc.of $5^{\text {th }}$ Ins.Conf.on HydroScience and Engineering. Warsaw . Poland(CR-Room and Booklet of Abstracts) .

7. Negm, A.M.,Al-Brahim A.M.and Alhamid A.A.2002."Combined Flow Over Weirs and Under Gates". Journal of Hydraulic Research, 40(4).

8. Negm, A.M.2002C. "Discution of Analysis and Formation of Flow Through Combined V-notch Gate Device". By Alhamid A.A., Journal of Hydraulic Research 40(4).

9. Rajaratnam, N.(1977),"Free Flow Immediately Below Sluice Gates, proc. ASCE, J. Hydraulics Div., Vol.103 No.Hy4, pp.345-351.

10. Subramanya, k.( 1986) "Flow in Open Channels" ,pp.219-226, Tata Mc-Graw-Hill Publishing Company Ltd., New Delhi, First Revised Edition, $7^{\text {th }}$ reprint. 